\title{
Teachers' Perceptions about the Existing CBSE Secondary Grade English Syllabus and the Need for Inclusion of Multimodality
}

\author{
Deepak Kumar ${ }^{*}$, Pushp Lata \\ Department of Humanities and Social Sciences, BITS Pilani, Pilani Campus, Rajasthan, India \\ Received September 8, 2020; Revised November 18, 2020; Accepted November 29, 2020
}

\section{Cite This Paper in the following Citation Styles}

(a): [1] Deepak Kumar, Pushp Lata , "Teachers' Perceptions about the Existing CBSE Secondary Grade English Syllabus and the Need for Inclusion of Multimodality, "Universal Journal of Educational Research, Vol. 8, No. 12A, pp. 7870-7880, 2020. DOI: 10.13189/ujer.2020.082576.

(b): Deepak Kumar, Pushp Lata (2020). Teachers' Perceptions about the Existing CBSE Secondary Grade English Syllabus and the Need for Inclusion of Multimodality. Universal Journal of Educational Research, 8(12A), 7870-7880. DOI: 10.13189/ujer.2020.082576.

Copyright $\mathrm{C} 2020$ by authors, all rights reserved. Authors agree that this article remains permanently open access under the terms of the Creative Commons Attribution License 4.0 International License

\begin{abstract}
The advancements in communication and information technology have necessitated changing the traditional ways of teaching and learning. Educators have etched the space and scope to integrate multimedia and technology for better learning outcomes. Like other subjects, teachers and syllabus designers of English subject have also made an effort to integrate multimedia and technology into the English syllabi through retention of the best of the ongoing practices in ELT and by further improvising it to cater to the changing teaching-learning needs. The present study aims to understand the teachers' views regarding the efficacy of the existing syllabus of English for secondary grade prescribed by Central Board of Secondary Education (CBSE), New Delhi. The study also aims to determine whether the teachers feel the need of inclusion of Multimodality in the syllabus to improve its quality and delivery in the classroom. Sample for this study $(n=176)$ was drawn from the teachers teaching in various secondary schools affiliated to the CBSE. For this purpose, a questionnaire based on ' 5 point Likert scale' was used as an instrument to collect responses from the teachers. The responses were quantitatively analyzed. Correlation among the parameters was validated to test the relationship among them. The study establishes a strong relationship among the different parameters of syllabus and further verifies that the teachers feel that there is a need for further improvement in the syllabus in all the parameters of syllabus design. The study recommends the integration of
\end{abstract}

Multimodality in the syllabus for improving its effectiveness. Such integration will make the comprehension easier and more interesting. It will also add to the curiosity of the students.

Keywords Multimodality, Efficacy, Parameters, Syllabus Designing, Teachers' Perception

\section{Introduction}

English Language Teaching (ELT) has undergone voluminous changes over the years due to a revolution in technology and social media. Their influence has extensively changed the ways language is used for communication purpose these days. Graddol [1] aptly explains that any change in the pattern of communication or the structure of social relationships is likely to lead to a change in language use. Considering the influence and challenges of using educational technology in ELT, Alqahtani states how it incorporates a wide array of things such as an innovative application of methods, tools, materials, devices, systems, and strategies etc. [2] Screen (laptop, mobile phones, smart boards, etc.) has influenced the learners who are digital natives (Mark Prensky, 2001) and their learning styles in an unafathomable ways across all geographic boundaries. In fact, technologies have 
opened new communicative possibilities, enabling and constraining new, hybridized genres that can challenge the literacy traditions [3]. The technological advancements in recent times have facilitated the teachers and syllabus designers with an innovative option of embedding technology into the syllabi, thus making them better structured and more effective. In 2003, Bax [4] predicted that learning technologies are becoming more normalised in language classrooms, and Pegrum [5] claimed that teachers are beginning to "stop seeing them as technologies and start seeing them as tools which suit some purpose and not others". Easy access to multimedia devices, gadgets and gizmos, and internet has made it possible for the teachers and learners to access all sorts of required information with a single click. While talking about the impact of ICT, Ratheeswari [6] claims that these changes are felt more at school levels because ICT tools provide both students and teachers with more opportunities in adapting learning and teaching to individual needs. Internet and multimedia devices have added their capacity for further shaping the teaching-learning process, including human presence and merger of technology into the process. Simultaneously, many developments have taken place in the teaching-learning approaches and methods such as Blended Learning, Project Based Learning, Multimedia Learning, ICT, Web 2.0, Multiliteracies, and Multimodality. Many factors like the needs of the learners, business and industrial revolutions and expansion, the advent of technology etc. have contributed significantly in revolutionising these approaches, methods and techniques of language teaching all over the world. Before the technology enabled teaching learning, Experiential learning by David Klob brought a major shift in education as he claimed, "Learning is the process whereby knowledge is created through the transformation of experience" [7]. However, the major paradigm shift came with the change setter approach to teaching and learning i.e. the concept of Multimodality.

The technology-initiated communication behavior has made it mandatory to talk about how language users acquire a language. There are various models of second-language acquisition (SLA) proposed by different theorists. Corder [8] and Selinker [9] proposed that language is acquired through the intrinsic linguistic processes and individual linguistic systems possessed by learners. In his theory of Input Hypothesis, Krashen [10] asserted that humans acquire language by understanding messages, or by receiving 'comprehensible input'. Michael Long [11] (Interaction hypothesis) and Merrill Swain [12] (Comprehensible Output hypothesis) offered their concepts to understand the process of SLA. All these theories reflect that learners learn a language in correspondence to the kind of learning inputs one is provided with or is considered as an intrinsic linguistic system which depends on an individual's cognitive level and learning style. But there is another important dimension to learning i.e. 'meaning-making', it is very important in today's technologically advanced world where just written and spoken words cannot claim to create the desired meaning. According to Adami [13] all communication is multimodal and each mode has specific affordances arising from its materiality and from its social histories. Gunther Kress [14] defines mode as "a socially and culturally shaped resource for making meaning. Image, writing, layout, speech, moving images are examples of different modes."

Multimodality incorporates interplay among all modes i.e. visual, spoken, gestural, written, three-dimensional, spatial, etc. all of which contribute towards meaning-making. The multimodal aspect of communication necessitates taking into account the different modes of communication which have a significant impact on the process of meaning-making in today's world. Adami [13] states that the social impact of digital technologies for text production, among other factors, has clearly stated that texts are multimodal and hence language alone cannot suffice to explain meaning made through them. She further argues that the digital texts we daily engage with make meaning through the combined use of colour, writing, sound, images, and layout, at least. Today's world has numerous examples of multimodal interactive interfaces like ATM machines, mobile phones, train and bus ticket vending machines, classroom interactive boards, etc. Multimodality is an inter-disciplinary approach that understands communication and representation to be more than about language. It has been developed over the past decade to systematically address much-debated questions about changes in society, for instance in relation to new media and technologies [15]. As such, it has helped the process of meaning-making in various disciplines like medicine, music, mathematics, science, communication, semiotics, art, painting, education, etc. As Jewitt [16] observes, the phenomenon of multimodality has generated interest "across many disciplines against the backdrop of considerable social change".

Since Multimodality offers multiple modes with socially and culturally appropriated resource for meaning-making, researchers find it all the more suitable for English Language Teaching. Considering its usefulness, countries like Singapore and Australia redesigned their school syllabuses of English language based on Multimodality. "Evidence of multimodal literacy can be inferred from the latest review of the English syllabus. In recognition of the multimodal nature of texts and the ubiquity of multimedia texts, the English Unit of the Curriculum Planning and Development Division (CPDD) has, in its English Language Syllabus 2010, included two more aspects to the existing areas of language teaching. They are the aspects of 'Viewing' and 'Representing"' [17]. Australian curriculum also stresses 
upon the need of multimodal forms of expression. While discussing the multimodal aspect in curriculum of English in Australia, Beavis [18] asserts that "texts for study include oral, print and multimodal forms, and students are encouraged/required to 'interpret, appreciate, evaluate and create' literary texts in many forms and modes".

The multimodal interventions provide opportunities and better exposure to the teachers and learners in the use of the technology-driven modern-day language systems and towards understanding and creating multimodal texts and their meanings. Nevertheless, the teachers who try using technology in the classroom face numerous challenges. According to Johnson, Jacovina, Russell, \& Soto [19] "although teachers generally appreciate the benefits of educational technologies, they often find smooth and effective integration of new educational technologies challenging. From acquisition of new technology equipment to adaptation of curricula and teaching techniques to incorporate new educational tools, technology integration presents significant challenges to educators at each level of school systems." Hyndman [20] also enumerates some challenges faced by teachers while integrating technology into the classroom. According to him teachers face challenges like pressure to become digital experts, students' distraction, effect on lesson time and flow, lack of technology at home, teachers' lack of belief in technology, lack of proper ICT support, infrastructure or time.

The advantages of multimodality in the syllabus and the challenges posed by it call for a study on the need of inclusion of such tools in the syllabus in Indian context. Hence, in the light of these facts, the present study evaluates the existing syllabus of English for secondary grade offered by CBSE in India and tries to map the extent to which it accomplishes the set objectives and also explore the need and feasibility of including multimodality in the syllabus. To examine both these attributes, the researchers decided to reach out to the teachers teaching English to secondary grade in the CBSE affiliated schools and know their insights about it. Teachers were selected as respondents because they play a vital role in implementing the syllabus in the classroom. They have a lot of experience of understanding the level of achievement of the students in different aspects of syllabus. As Ratheeswari [6] states that teacher is the main part of the educational field in our society" they conduct all the syllabus-guided activities in and outside the classroom and can give highly valuable inputs regarding the existing syllabus and the improvements needed.

Thus, the present study has worked upon two objectives: First, to know and understand the teachers' perception regarding the efficacy of the existing syllabus of English for secondary grade prescribed by CBSE and second, to know the teachers' views regarding the inclusion multimodality in the syllabus of English for secondary grade.

\section{Literature Review}

Education is an integral part of an individual's development and growth. Among all the levels, Secondary education, in particular, is significant in students' lives as it provides them a path to tread and a broader perspective and skillsets required for career growth and future challenges in life. Gargesh [21] states that it is "a crucial stage in the educational hierarchy as it prepares students for higher education and at times, also for employment." Secondary grade is an important level in the lives of the students as it defines and shapes their future lives. The vision document for secondary grade [22] issued by the Department of Secondary Education (DSE) in National Institute of Education (NIE) under National Council of Educational Research and Training (NCERT), Ministry of Human Resource Development (MHRD), Govt. of India states that "a child's future can depend a lot on the type of education s/he receives at the secondary level" as it "serves as a link between the elementary and higher education" This is for the first time in the students' lives that they face a national level examination and go through a very important transitional period i.e. adolescence to young hood which matures them mentally and physically. At this juncture, what they study in the classroom becomes imperative as all the learning at school, majorly depends on what they are taught in the class. Thus, the prescribed syllabus and textbooks guide and instruct the teacher about the objectives, content, time, evaluation and method to a large extent.

Teaching of English becomes essential because the ability to communicate in English empowers the students to become globally fit and have an access to use opportunities in the job market. Globalisation and innovations in technology have reflected in a huge change in the communication needs. Therefore, the education systems also need to revise their syllabuses from time to time. It was in the 1980s when the CBSE made a major change in the English syllabus where it gave more importance to the language functions than literature. According to Kumar, Philip \& Kalaiselvi [23] "the CBSE changed the English syllabus in the 1980s where more importance was given to the language functions rather than literature." This was the first instance when the syllabus designers felt the need of introducing a language based syllabus in order to pay more attention towards communication skills and "slowly CLT started creeping into Indian classrooms" [23]. After this, in 1993-94 the syllabus was revised and "The English Communicative Course was introduced at secondary level. "Though the course materials have been restructured subsequently in 1995, 1997, and 2003, a complete revision was undertaken only in 2009 when the Main Course Book, Work Book and Literature Reader for class IX were revised on the basis of feedback received from teachers, students and ELT professionals" [24]. This is important to 
know that as per the Citizen's Charter at CBSE website [25] "The Board as on 21-10-2019 has 22030 schools in India and 232 schools in 27 foreign countries. There are 1138 Kendriya Vidyalayas, 2727 Government/Aided Schools, 17553 Independent Schools, 598 Jawahar Novodaya Vidyalayas and 14 Central Tibetan Schools" affiliated to the board. The numbers suggest that there is a phenomenal number of students studying in the schools affiliated to the CBSE.

The National Curriculum Framework (NCF) has been revised thrice in 1988, 2000 and 2005 after the publication of the NCF for the first time in 1975. The present CBSE syllabus has been designed on the guidelines provided by the NCF-2005. NCF-2005 [26] emphasizes upon the merger of input material so as to enhance the quality of education in the field of language teaching as it recommends that "Input-rich communicational environments are a prerequisite for language learning, whether first or second. Inputs include textbooks, learner-chosen texts, and class libraries, allowing for a variety of genres: print (for example, Big Books for young learners); parallel books and materials in more than one language; media support (learner magazines/newspaper columns, radio/audio cassettes); and "authentic" materials" [26]. Though NCF 2005 recommends the above materials but the existing syllabus does not have enough multimedia and ICT support and the same has been substantiated by this study.

Several studies have been carried out on the review of textbooks and syllabus design in India and abroad. Singh $\&$ Choudhary [27] evaluated the appropriacy of the textbooks prescribed by the Board of Secondary Education, Rajasthan, (BSER) and CBSE, New Delhi. They evaluated the text books focusing on the parameters of 'Aim and objectives', 'Design and Organisation', 'Language Content', and 'Additional Teaching Aids'.

Agrawal, Chakraborty, Gollapudi, Kannan and Kenthapadi [28] evaluated the textbooks of History (Grade XII), Sociology (Grade XII) and Science (Grade X) on the parameters of Focus, Unity and Sequentiality. They proposed that that well-written textbooks exhibit the properties of Focus, Unity and Sequentiality. Tasildar [29], on the other hand, explored the need to revamp the syllabus of UGC NET in India. The study stated the need of reviewing the syllabus with the changing time continually. The researcher suggested several ways for improving the syllabus by integrating the syllabus of UGC NET with the syllabus of MA in the universities.

The study carried out by Rahimpour \& Hashemi [30] evaluated three English language textbooks used at high schools in Iran from English teachers' point of view. The study was based on the parameters of vocabulary, reading, grammar, language functions, and pronunciation practice. The researchers primarily focused towards the different aspects of language and their integration in the textbooks.

Sheldon [31] states that ELT coursebook publishing is a multi-million-pound industry, yet the whole business of product assessment is haphazard and under-researched. In the same way, the studied referred above reflect that many researchers have evaluated the textbooks and syllabi used at different levels. At the same time, the need of evaluation of textbooks and syllabus has always been felt in the language subjects. Different experts and researchers have used different parameters to assess the textbooks and syllabi on the basis of some theories and related focus areas. Although we come across many such studies in this field but they do not address the issues with the syllabus of secondary grade in India. Therefore, the present study evaluates the syllabus and the effectiveness of the textbooks to observe the extent to which the syllabus achieves the stated objectives and the need of further improvisation in the syllabus through multimodality.

\section{Parameters of Syllabus Design}

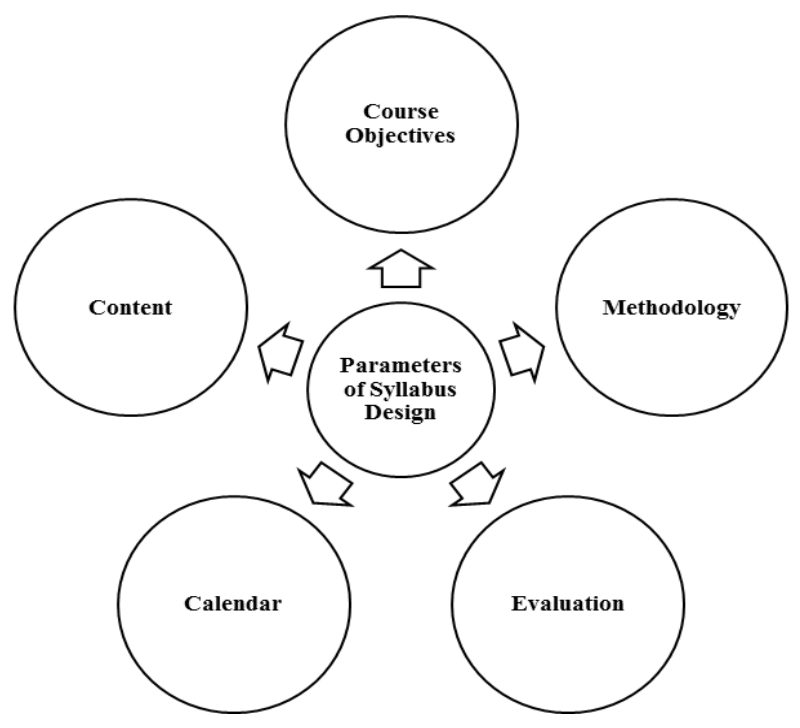

Figure 1. Parameters of Syllabus Design

Since the present study focusses on the evaluation of the existing syllabus of English subject at the secondary grade, it becomes important to know the parameters of syllabus which are attended through it. Syllabus has been defined in various ways by different experts. Some of them feel that it involves basic specifications with selection, definition and grading of content $[32,33,34,35]$. The inclusion of only content and its specification and grading has been regarded as a narrow approach by Nunan [36] who demarcates broad and narrow approaches to syllabus design. He states that those who adopt broader view, question the separation of content and methodology in the syllabus. Candlin \& Breen [37,38] feel that methodology and evaluation can be considered part of syllabus specification. But the view to which the present paper subscribes is given by Datzman [39] and Dubin \& Olshtin [40] who state that syllabus design has five major parameters as objectives, content, time, method, and 
evaluation (Figure 1). Thus, in the present study, the teachers' views were collected on these five parameters of the existing secondary grade syllabus of English in CBSE schools.

Syllabus designers require defining the course objectives well in advance before selecting and grading the course content. Researchers have held a strong opinion about the fact that curriculum should clearly communicate the expected outcomes in a hierarchical relationship. It helps the teachers to translate the same in the classroom as a practitioner. According to Yalden [32] the syllabus "concerns, in the first instance, the ends of the instruction". The syllabus of a language refers to what is to be taught as content. Allen [33] also claims that syllabus "is concerned with specification of what units will be taught". "Selection and grading of content follow goal and objective setting" [36].

Methodology, as we understand, concerns with the 'how' part of the delivery of the content in the classroom. Dubin and Olshtin [40] state that syllabus describes "how it is to be taught, suggesting procedures, techniques and materials". Candlin [37] highlights the importance of making purposes (objectives), content, methods, and evaluation interdependent with a particular focus on the integration of content and experience. Yalden [32] discusses the importance of course calendar and refers to it as "pragmatic efficiency" or economy of time.

Thus, syllabus design has interplay among all these parameters. Syllabus creates a base on the evaluation of the learning of the content. It defines ways of "how it is to be evaluated?" [40]

Nunan [36] also believes that the effective planning, implementation, and evaluation of language learning and teaching requires an integrated approach covering all the aspects of syllabus and interrelating them.

Therefore, for the data collection a questionnaire which was used as a method, covers all the above five parameters. The following section discusses the tool, sample design and analysis of data.

\section{Method}

In order to understand the perception of CBSE English teachers about the efficacy of existing syllabus and their views on the inclusion of Multimodality, a questionnaire was framed containing 32 statements on a five-point likert scale. As mentioned above, the questionnaire focused on the five major parameters of syllabus design. The first 23 questions of the questionnaire were framed around these five parameters and the remaining 9 questions attempted to know the respondents' views regarding the inclusion of multimodality in the syllabus of secondary grade. The questions related to the use of multimedia in teaching were taken from the questionnaire used in the study by Antonietti \& Giorgetti M [41]. Face validity and content validity of the questionnaire were evaluated by experts and changes were made as per the suggestions given by the experts. The responses were obtained on a 5-point Likert scale where 1 meant 'Strongly Disagree'; 2 meant 'Disagree'; 3 meant 'Uncertain'; 4 meant 'Agree' and 5 meant 'Strongly Agree'.

The questionnaire design consisted of the following three parts:

\begin{tabular}{|l|l|}
\hline Part I & Demographic information \\
\hline Part II & $\begin{array}{l}\text { Teachers' perception about the existing syllabus and } \\
\text { its effectiveness }\end{array}$ \\
\hline Part III & $\begin{array}{l}\text { Teachers' opinion about the inclusion of } \\
\text { Multimodality in the syllabus and its effectiveness } \\
\text { (IMS) }\end{array}$ \\
\hline
\end{tabular}

The data for this study was collected using Purposive Sampling under the non-probability sampling technique. This sampling technique was chosen for collecting the relevant data for study because sampling techniques help the researcher decide the purpose that their "informants (or communities) could serve, and go out to find some" [42]. The target respondents were the teachers teaching secondary grade in the schools affiliated to CBSE, New Delhi. The respondents were PGTs (Post Graduate Teachers) and TGTs (Trained Graduate Teachers) in different government and private schools in the districts of Jhunjhunu, Rewari and Jaipur. They were selected because they were teaching English subject in these schools. The average experience of the teachers was 16.34 years. The researcher administered the questionnaire to 176 English teachers from different CBSE affiliated schools.

The data obtained was analysed using quantitative techniques. The data was analysed using SPSS (Statistical Package for the Social Sciences) software. Reliability of the questionnaire was checked using Cronbach's Alpha for the individual parameters and the whole questionnaire separately. Further, correlation among all the parameters was tested to ascertain inter-dependability among variables. Mean values were calculated to understand the perception of teachers towards different questions under all the parameters. Divergent stacked bar charts were used to visually analyze the data and compare the responses among different categories. As mentioned by Weitz [43] "Diverging bar charts allow comparisons between different items or categories. Its main application is in the visual analysis of surveys or questionnaires developed using the Likert scale." A comparative study of the responses of the respondents among different parameters of syllabus design and their responses about the inclusion of Multimodality in the syllabus was made using these charts.

\section{Results and Analysis}

There were 176 teachers who responded to the 
questionnaire. Majority of the teachers worked in private schools, as 142 teachers out of 176 teachers were teaching in private schools whereas 34 teachers were teaching in government schools. When it comes to durational functionality of the schools where these teachers worked, 6 schools were residential in nature whereas 43 schools were day schools. 112 teachers worked as TGTs (Trained Graduate Teacher) whereas 64 teachers worked as PGTs (Post Graduate Teacher) in their respective schools. It is interesting to note that 41 teachers were in age bracket of 23-30 years, 44 teachers were in age bracket of 31-40 years, 59 teachers were in age bracket of 41-50 years, and 32 teachers were in age bracket of 51-60 years. This data reflects that most of the teachers belonged to age group of 41-50 years. The respondents had varied levels of experience in terms of years of teaching English at the secondary grade. As mentioned above, the average experience of the respondent teachers was 16.34 years. This shows that their responses are quite valuable and credible as they had the enough understanding into the way the existing syllabus and the ways in which the syllabus can be improvised to make it better learning outcome oriented.

The data was analysed using quantitative techniques. Reliability of the whole questionnaire was measured. Table 1 shows the Cronbach's Alpha $(\alpha)$ values of the whole questionnaire. Cronbach's Alpha for the scale of 32 items was found to be .853 . Reliability of all the variables was measured separately as well. Cronbach's Alpha of the 6 items under the parameter of Course Objectives was found to be .787 . The Cronbach's Alpha of this scale for the 5 items related to the parameter of Course Content was found to be .783 . For the two items to check the views of teachers regarding the third parameter i.e. course Calendar, the Cronbach's Alpha was found to be .706. The questionnaire had 4 items to check the teachers' perception regarding the aspect of methodology. The responses were measured and the Cronbach's Alpha of this scale was found to be .704 . The study endeavored to evaluate the teachers' views about the parameter of evaluation with 6 questions on five-point likert scale and the Cronbach's Alpha of this scale was found to be .832 .

The third part of the questionnaire intended to know the teachers' views on inclusion of Multimodality in the syllabus. The responses to this aspect were obtained on a 5-point Likert scale with 9 questions and the Cronbach's Alpha of this scale was .957 .

Table 1. Reliability Statistics

\begin{tabular}{|c|c|c|}
\hline Parameters & $\begin{array}{l}\text { Number of } \\
\text { Items }\end{array}$ & Cronbach's Alpha \\
\hline Course Objectives & 6 & .787 \\
\hline Course Content & 5 & .783 \\
\hline Course Calendar & 2 & .706 \\
\hline Methodology & 4 & .704 \\
\hline Evaluation & 6 & .832 \\
\hline $\begin{array}{l}\text { Teachers' Views about the } \\
\text { inclusion of Multimodality } \\
\text { in the syllabus }\end{array}$ & 9 & .957 \\
\hline \multicolumn{2}{|c|}{$\begin{array}{l}\text { Cronbach's Alpha for the whole } \\
\text { questionnaire }\end{array}$} & .853 \\
\hline
\end{tabular}

Multivariate techniques were used to test the relationship among the different variables/parameters. Descriptive statistics were calculated using measures of mean and standard deviation. Table 2 depicts the means, standard deviation and correlations among the different variables.

"The correlation coefficient is a statistical measure of the strength of the relationship between the relative movements of two variables. The values range between -1.0 and 1.0. A calculated number greater than 1.0 or less than -1.0 means that there was an error in the correlation measurement. A correlation of -1.0 shows a perfect negative correlation, while a correlation of 1.0 shows a perfect positive correlation. A correlation of 0.0 shows no linear relationship between the movement of the two variables" [44].

Table 2. Correlation Diagnostics

\begin{tabular}{|l|c|c|c|c|c|c|c|c|}
\hline & Mean & SD & 1 & 2 & 3 & 4 & 5 & 6 \\
\hline 1. Course Objectives & 2.5000 & .71691 & 1 & $.750^{* *}$ & $.689^{* *}$ & $.629^{* *}$ & $.748^{* *}$ & $-.472^{* *}$ \\
\hline 2. Course Content & 2.5829 & .73348 & $.750^{* *}$ & 1 & $.870^{* *}$ & $.634^{* *}$ & $.765^{* *}$ & $-.451^{* *}$ \\
\hline 3. Course Calendar & 2.7613 & .92883 & $.689^{* *}$ & $.870^{* *}$ & 1 & $.651^{* *}$ & $.685^{* *}$ & $-.276^{* *}$ \\
\hline 4. Methodology & 2.6903 & .75828 & $.629^{* *}$ & $.634^{* *}$ & $.651^{* *}$ & 1 & $.740^{* *}$ & $-.180^{* *}$ \\
\hline $\begin{array}{l}\text { 5. Evaluation } \\
\text { 6. Inclusion of Multimodality in } \\
\text { the Syllabus (IMS) }\end{array}$ & 2.6174 & .73534 & $.748^{* *}$ & $.765^{* *}$ & $.685^{* *}$ & $.740^{* *}$ & 1 & $-.393^{* *}$ \\
\hline \\
**. Correlation is significant at the 0.01 level (2-tailed)
\end{tabular}


The correlation matrix in this study provides evidence of the fact that the parameters of syllabus design have strong positive correlation amongst themselves. The parameter of Course Objectives has a mean value of $\mathrm{M}=2.5000$ and Standard deviation value of $\mathrm{SD}=.71692$, Course Content $(\mathrm{M}=2.5830, \quad \mathrm{SD}=.73348)$, Course Calendar $\quad(\mathrm{M}=2.7613, \quad \mathrm{SD}=.92883), \quad$ Methodology $(\mathrm{M}=2.9603, \quad \mathrm{SD}=.75828), \quad$ Evaluation $\quad(\mathrm{M}=2.6174$, $\mathrm{SD}=.73535)$ and Inclusion of Multimodality in the Syllabus (4.0051, $\mathrm{SD}=.83112$ ) have strong relationships amongst themselves. Course Objectives have a strong relationship with Course Content $(\mathrm{r}=.750)$ Evaluation also has a significant relationship with Course Objectives $(\mathrm{r}=.748)$. Course content has a significant effect on the Evaluation $(\mathrm{r}=.765)$. The relationship between Course Content and Course Calendar is $r=.870$ which is a high degree of correlation between these two variables. The relationship of Course Objectives with Course Calendar and Methodology is significant with $\mathrm{r}=.689, \mathrm{r}=.629$ respectively.

The relationship of Course Content with Methodology is significant with $\mathrm{r}=.634$. Course Calendar also has significant relationship with Methodology and Evaluation with $\mathrm{r}=.651, \mathrm{r}=.685$ respectively. Methodology has significant relationship with evaluation with $r=.740$.

The correlation of IMS with the different parameters of syllabus design has a negative relationship as suggested by the data. It has $\mathrm{r}=-.472, \mathrm{r}=-.451, \mathrm{r}=-.276, \mathrm{r}=-.180$, and $\mathrm{r}=-.393$ with the parameters of Course Objectives, Content, Calendar, Methodology and Evaluation respectively. It suggests that the teachers were of the opinion that the existing syllabus is not yielding the desired results and they feel positive about the Inclusion of Multimodality in the syllabus. It is substantiated by the mean values as well. The mean values for the five parameters are 2.50, 2.58, $2.76,2.69$, and 2.61 respectively but the mean value for IMS is 4.00 which shows a positive result on five-point likert scale from 'strongly disagree' to 'strongly agree'. The mean values show that the respondents are not satisfied with the practical functional aspects of the different parameters of the syllabus and they feel that the syllabus needs improvements in all the aspects. On the other hand, they felt positive about the inclusion of multimodality in the syllabus which is clearly suggested by the mean score of the responses under this factor which the study intends to find.

Further, the study explored to understand the views of the respondents through the divergent stacked bar chart for all the parameters of syllabus design and the field of Inclusion of Multimodality in the Syllabus. The chart shows the interpretation of the responses to the 6 items asked related to the achievement of course objectives defined for the secondary grade under CBSE (Chart 1). Out of 176 respondents, $2 \%$ strongly agree, $18 \%$ agree, $23 \%$ were uncertain $47 \%$ disagree and $12 \%$ Strongly disagree. It means that only $20 \%$ respondents felt that the Course Objectives set by the CBSE are being met through the syllabus; on the other hand, 59\% respondents felt that the objectives are not being achieved through the existing syllabus. The statistics hint at the requirement of some enhancements in the syllabus towards improved realisation of the objectives.

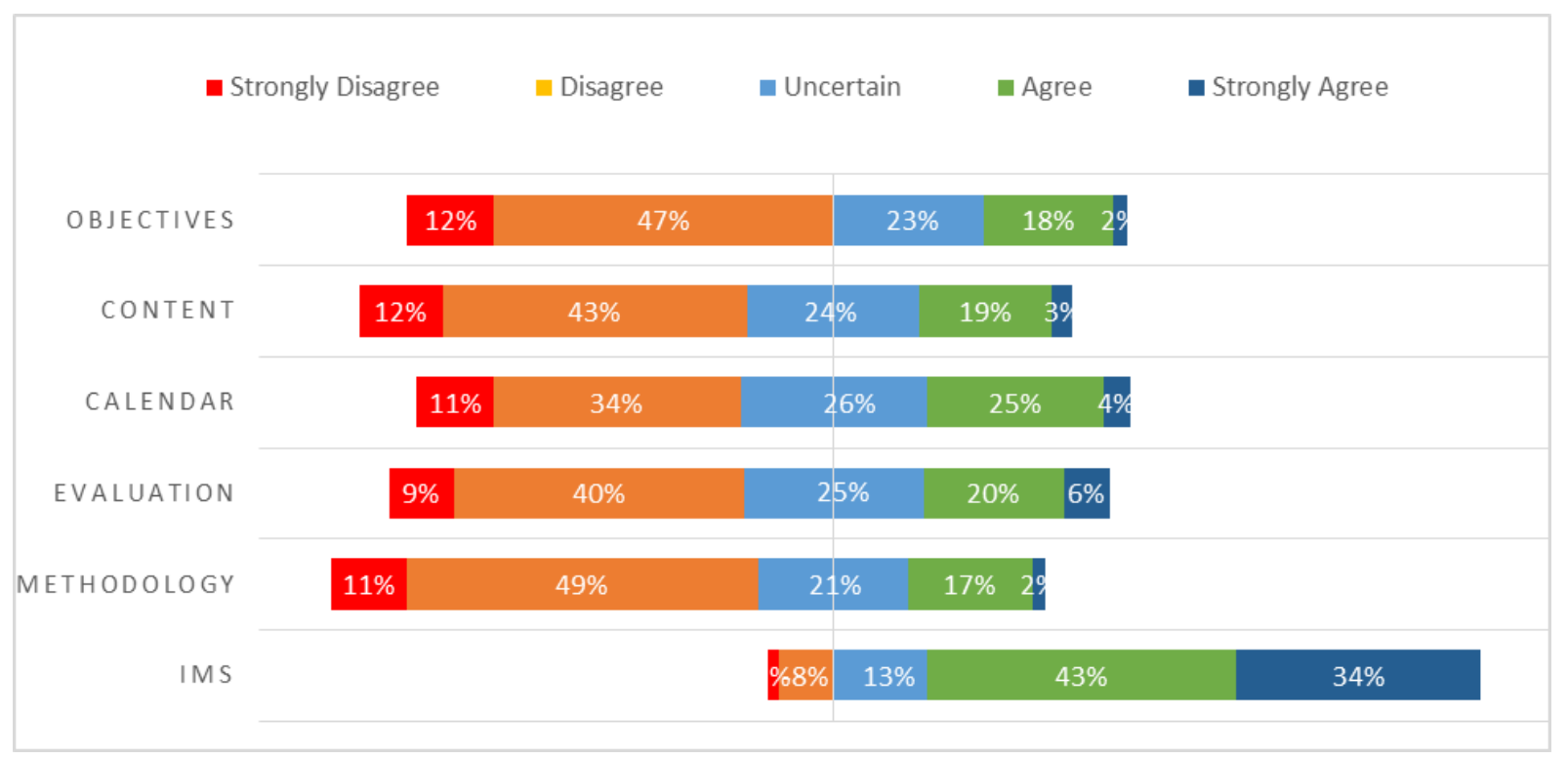

Chart 1. Parameter-wise Responses 
Responses to the 5 items checked for the second variable i.e. Course Content show that most of the respondents feel that the course content is not satisfactory as expected and needs to be worked upon. Only $22 \%$ of the respondents feel that the course content is appropriate whereas $24 \%$ of them were uncertain but a good number of them i.e. $55 \%$ believe that the course content is not at par with the standard and expectations and needs to be improved in order to meet the set objectives. The chart also reflects the responses to the third variable i.e. course calendar. It shows that $45 \%$ of the respondents feel that it is difficult to cover the whole syllabus as per the calendar because of its vastness which becomes unmanageable. However, $26 \%$ of them are uncertain and $29 \%$ of them feel that they are able to complete the syllabus/course content within the allotted frame of time as per the periods allotted for each topic and chapter by the CBSE. The results resonate that majority of the respondents find that syllabus is too massive so as to be covered as per the schedule suggested by the board.

Responses to the parameter 4 of syllabus design i.e. Evaluation indicate that $26 \%$ of the respondents feel that the existing system of evaluation is up to the mark and there is no need for any further improvisation. They think that the current approach to assessment and its procedures do not need any further changes as they feel that they are able to evaluate the skills of the students in all aspects and they also feel that the students' creativity and critical thinking can also be assessed through the existing system of evaluation. But $49 \%$ of the respondents feel that the system of evaluation which is being followed does not allow the evaluation of all skills effectively and thus needs to be improved upon. $25 \%$ of the teachers were uncertain regarding this aspect of syllabus.

The last parameter of syllabus design i.e. Methodology inquired about the suitability of the methodology suggested and provided by the syllabus to the teachers and students. $60 \%$ of the respondents feel that there is scope for improvement in this dimension whereas $21 \%$ of them were uncertain about it. Only 19\% of the respondents feel that the syllabus incorporates all the dimensions of holistic development and guides the teachers appropriately towards teaching the topics in an effective manner. They believe that the multimedia and visual support offered in the existing syllabus including text books and instructions in the handbooks is sufficient. But the data on the other side of the coin shows that most of the respondents feel that the syllabus does not provide sufficient multimedia and visual support for better and easier understanding of concepts. It shows that most of them are of the view that the syllabus has a huge scope for improvement in this regard.

Section II of the questionnaire was designed to collect responses from teachers regarding the inclusion of Multimodality in the syllabus. The questions were selected keeping in mind the need to include the multimodal tools and content in the syllabus. The respondents had to express their opinions as to whether the inclusion of Multimodality will enhance the quality of the syllabus or not. The respondents had to answer 9 questions for this parameter. Out of 176 respondents, a significant number i.e. $77 \%$ responded in favour of including Multimodal tools in the syllabus and with mean score of $4.0 .13 \%$ of the respondents were found to be uncertain about making a choice and only $10 \%$ of them felt that there is no need of including latest learning tools and Multimodality in the syllabus

The chart clearly indicates that the teachers' opinion about the dimension of IMS is positive and they believe that the inclusion of the multimodal tools like multimedia, internet \& technology can play an important role in improving the learning quotient of the students. They also believe that the use of such tools will facilitate the teachers and learners for easier learning of different concepts and their application.

\section{Discussion}

The present study has identified gaps and has mapped the scope of improvement in the existing syllabus of English for secondary grade of CBSE, New Delhi. As mentioned above, the study has checked and has established a significant relationship among all the five parameters of syllabus design i.e. course objectives, course content, course calendar, evaluation and methodology. It was also examined whether the inclusion of multimodality in the syllabus will enhance its quality. The study gives an evidence that the English syllabus of X grade of CBSE has certain gaps in almost all the dimensions. Many respondents felt that the syllabus lags in realising the course objectives such as enabling the learners to communicate effectively and appropriately in real-life situations; using English effectively for study purposes across the curriculum; in developing all the four language skills i.e. listening, speaking, reading and writing; in developing interest and understanding of literature; etc. The respondents also felt that the syllabus should be more application-oriented. They felt that the course content and activities should lead towards practical outputs wherein the students should be able to use English as a language of interpretation and communication in real-life situations. They feel that English should not remain merely a subject taught in the schools. An earlier study on textbook evaluation of CBSE Secondary Grade by Singh \& Choudhary [27] also concluded that the teachers were not fully satisfied with the textbook prescribed for Class $\mathrm{X}$ in terms of fulfilling the aims and objectives of teaching English.

It appears likely that the teachers feel the course content needs some enhancement so that it may be more helpful in achieving the course objectives. The study indicates that 
the teachers feel that the content should fit in the present day needs like developing their understanding and skills to adapt to different cultures and providing enough exposure to the students in the form of activities, online platforms, multimedia devices, and visual resources. Possibly, the teachers felt that the content gives less exposure to the students to understand and use grammatically correct English language in day to day life. They also felt that the syllabus should provide suitable content to develop creativity among students. The respondents were also of the opinion that the syllabus should give enough exposure to enhance the critical thinking skills of the students through activities, projects, tasks and by using other multimedia tools.

As far as the course calendar is concerned, it looks as if the respondents felt that the syllabus is a bit bulky and it becomes a little demanding for them to teach the literary section, conduct grammar exercises, writing items, and reading in the allocated time in an academic year. It seems like they felt that there is a need to revisit the syllabus and reduce the burden of the syllabus so that it can be completed well in time and all the activities can also be conducted.

Concerning the parameter of evaluation, the teachers felt that there is need of a more comprehensive system of evaluation which may allow them to test and evaluate the students' performance in a holistic manner. They felt that apart from testing the memory skills, the present system of evaluation needs to examine the application of the key concepts taught and also test the creativity and expression of students. The study suggests that there is need of more comprehensive approach towards testing all the skills of language including the students' proficiency in oral communication and critical thinking.

Since the study revolves around the need for inclusion of multimodality in the syllabus, the researchers tried to know from teachers to what extent the multimedia support and teaching tools have been provided and suggested by the existing syllabus. Most of the respondents have agreed that there is a dearth of multimedia support which is essentially required in the present time. The textbooks in the existing syllabus do not have sufficient visual support such as images, maps, graphs to help students understand the topics in an interesting way. The existing syllabus does not incorporate digital and online platforms that can help in improving teaching of the course contents with ease and interest. It also does not include the learning tools like email, blogs, writing and posting on Wikispace and using kahootz, etc. for developing the writing skills. The result substantiates the study by Singh and Choudhary [27] who concluded that the teachers of CBSE were not satisfied with all the aspects under the category of additional teaching aids and in the study, data reflected that most of the teachers complained about the inadequate teaching material on pronunciation and audio/visual aids in the existing syllabus. In brief, the syllabus has insufficient multimedia support which could enable the teachers make the understanding of the topics/chapters easier, interesting and attention grabbing for their students.

The study shows that majority of the respondents (77\%) are in favour of inclusion of Multimodality in the syllabus as they feel that Multimodality will improve the quality of the syllabus in various ways. They feel that the use of multimedia and digital resources can help in making teaching and learning more interesting and help the weak students learn better. The use of Multimedia computer-supported instructional tools can help students have an international perspective and make comprehension easier. Such tools can help the students learn faster and can make the concept application easier as they arouse the users' curiosity and involve them in the learning process effortlessly. Most of the respondents believe that the inclusion of multimedia will improve the syllabus and help in enhancing the understanding of concepts and develop critical thinking among students.

\section{Implication of the Study}

The findings from the present study are applicable to CBSE, New Delhi, its affiliated schools, their teachers and students. The teachers teaching in all these schools follow the syllabus as defined by the CBSE and they require to achieve the stated objectives while teaching the courses using the material, following the prescribed course calendar with appropriate methodology. The topics and material taught in the classes are evaluated through tests and exams periodically.

Since the study has indicated the gaps that exist in the current syllabus, it shows the need for improvisation on all the related aspects of syllabus and a careful reworking on setting the learning outcomes of the English course syllabus which could cater to the changing linguistic and communicative needs of today's learners is felt by the teachers. The literature review has revealed that it was in 2009 which means a decade ago, when the syllabus was last revised and it has not been revised since then. Therefore, it is high time that syllabus be revised and improved so that students may learn the relevant language skills which may develop their better communication skills and $21^{\text {st }}$ century skills and hence, enhance their employability. This study offers a fresh perspective on improvising upon the syllabus by including a new approach i.e. Multimodality in the syllabus. This study helps the syllabus designers at CBSE to redesign and restructure the syllabus on the lines of Multimodality for boosting the learning with the new technologies and by making use of an array of modes which may create better interest in learning as all the learners will get to learn in their preferred ways in the new syllabus designed with multimodal approach. The study corroborates the views of 
Kumar \& Lata [45] who emphasize upon the need of developing the curriculum "keeping in mind the latest technological advancements and the effects which they have created in the dissemination of knowledge and communication."

As Hämäläinen \& Cattaneo [46] state that the "education can benefit from the opportunities of technological development, such technologies may create new challenges for teachers". Therefore, the suggested syllabus will demand upskilling of the in-service teachers. Gressard and Loyd [47] stated that 'teachers' attitudes toward computers are a key factor in the successful implementation of ICT in education". So, the present study has its usefulness for the teachers also who need to update their methodology, efficiency, ability, knowledge and motivation in the current changing scenario. The study resembles the outcomes of another study by Demirdöken [48] on Turkish EFL students where he concluded that that "rather than just learning the target language, technology will foster their learning processes".

Thus, the results of the study have paved way towards understanding the issues in the existing syllabus, keeping in mind all the parameters of syllabus design. It has not restricted itself to study only the effectiveness of the existing syllabus but it has gone beyond it and has analysed the possibility of improvising and upgrading the syllabus by including multimodality and associated methodology and teaching tools in the syllabus.

\section{REFERENCES}

[1] Graddol, D. The Future of English. London: British Council, 1997.

[2] A, Alqahtani. The Use of Technology in English Language Teaching. Frontiers in Education Technology. 2. p168. 10.22158/fet.v2n3p168, 2019.

[3] Madson, Michael. [Review of Multimodal Literacies and Emerging Genres, edited by Tracey Bowen and Carl Whithaus. Pittsburgh: University of Pittsburgh Press]. 2013.

[4] Bax, S. CALL - past, present and future. System 31/1: 1328. 2003

[5] Pegrum, M. From blogs to bombs. Crawley: UWA Publishing. 2009.

[6] Ratheeswari, K. Information Communication Technology in Education. Journal of Applied and Advanced Research. 3. 45. 10.21839/jaar.2018.v3iS1.169. 2018.

[7] Kolb, David. Experiential Learning: Experience As The Source Of Learning And Development. 1984.

[8] Corder, S. The Significance of Learner Errors. Iral-international Review of Applied Linguistics in Language Teaching - IRAL-INT REV APPL LINGUIST. 5. 161-170. 10.1515/iral.1967.5.1-4.161. 1967.
[9] Selinker, Larry. Interlanguage. Iral-international Review of Applied Linguistics in Language Teaching - IRAL-INT REV APPL LINGUIST. $10 . \quad 209-232$. 10.1515/iral.1972.10.1-4.209. 1972.

[10] Krashen, Stephen. The Input Hypothesis: Issues and Implications. New York. Prentice Hall. 1985.

[11] Long, M. H. The role of the linguistic environment in second language acquisition. In W. C. Ritchie, \& T. K. Bhatia (Eds.), Handbook of second language acquisition (pp. 413-468). New York: Academic Press. 1996.

[12] Swain, Merrill. Problems in Output and the Cognitive Processes They Generate: A Step Towards Second Language Learning. Applied Linguistics - APPL LINGUIST. 16. 371-391. 10.1093/applin/16.3.371. 1995.

[13] Adami, Elisabetta. Multimodality. Oxford Handbook of Language and Society edited by Ofelia García, Nelson Flores, and Massimiliano Spotti. DOI:10.1093/oxfordhb/97 80190212896.013.23. 2016.

[14] Kress, Gunther. Multimodality.: A Social Semiotic Approach to Contemporary Communication. New York: Routledge. p. 79. 2010.

[15] Bezemer, Jeff. What is Multimodality. Retrieved from https://mode.ioe.ac.uk/2012/02/16/what-is-multimodality/ February 12, 2012.

[16] Jewitt, C. Handbook of Multimodal Analysis, London: Routledge. 2009.

[17] O'Halloran, K. L. \& Lim, F. V. Dimensions of Multimodal Literacy. Viden om Læsning. Number 10, September 2011, pp. 14-21. Nationalt Videncenter for Laesning: Denmark. 2011

[18] Beavis, Catherine. Literary English and the Challenge of Multimodality. Changing English. 20. 10.1080/1358684X.2 013.816527. 2013.

[19] Johnson, A. M., Jacovina, M. E., Russell, D. E., \& Soto, C. $\mathrm{M}$. Challenges and solutions when using technologies in the classroom. In S. A. Crossley \& D. S. McNamara (Eds.) Adaptive educational technologies for literacy instruction (pp. 13-29). New York: Taylor \& Francis. 2016.

[20] Hyndman, Brendon. Ten reasons teachers can struggle to use technology in the classroom. The Conversation 2018. Retrieved from https://theconversation.com/ten-reasons-tea chers-can-struggle-to-use-technology-in-the-classroom-101 114

[21] Gargesh, Ravinder. Miles to go...Secondary English Language Education in India. Secondary School English Education in Asia from Policy to Practice Ed. Bernard Spolsky and Kiwan Sung. Routledge Critical Studies in Asian Education. New York, 2015.

[22] Vision Document for Secondary Grade, DSE, NIE, NCERT, New Delhi, 2010.

[23] Kumar, N. Uttham, Philip, Priya, Kalaiselvi, A. The Application of CLT to Teaching English as a Second Language - An Assessment of Practice in India. International Journal of Humanities and Social Science Invention. www.ijhssi.org Volume 2 Issue 5 || May. 2013\| PP.24-29. 2013. 
[24] Joshi, Vineet. Interact in English Literature Reader, New Delhi. CBSE. 2011.

[25] Citizen's Charter. Central Board of Secondary Education (CBSE)

https://cbse.nic.in/newsite/attach/CitizenCharter\%2008.11.2 019.pdf accessed on 22 March 2020.

[26] National Curriculum Framework-2005, National Council of Research and Training. 2005.

[27] Singh, Rajni \& Choudhary, Sanjiv Kumar. Evaluation of English Textbooks for Class $\mathrm{X}$ Prescribed in BSER and CBSE Schools. Indian Educational Review. NCERT. July 2015.

[28] Agrawal, R., Chakraborty, S, Gollapudi, S., Kannan A., \& Kenthapadi, K. Quality of textbooks: An empirical study. Retrieved from http://research.microsoft.com/pubs/163747/ qualityOfTextbooksAnEmpiricalStudy-dev12.pdf. 2012.

[29] Tasildar, Ravindra B. A Critical Appraisal of the Syllabus of the University Grants Commission's National Eligibility Test in English. International Journal of Social Sciences and Humanities. Vol. 1. pp.32-38. June 2012.

[30] Rahimpour, Massoud \& Hashemi, Raheleh. Textbook Selection and Evaluation in EFL Context. World Journal of Education. 1. 10.5430/wje.v1n2p62. 2011

[31] Sheldon, L. E. Evaluating ELT Textbooks and Materials. ELT Journal. 4. pp. 237-46. 1988.

[32] Yalden, Jenice. Syllabus Design in General Education: Options for ELT. In C.J. Brumfit (Ed.) General English Syllabus Design (pp.13-22). Pergamom Press. 1984.

[33] Allen, J.P.B. General-Purpose Language Teaching: A Variable Focus Approach. In C.J. Brumfit (Ed.) General English Syllabus Design (pp.61-74). Pergamom Press. 1984.

[34] Stern, H.H. Review and Discussion. In C.J. Brumfit (Ed.) General English Syllabus Design (pp.5-12). Pergamom Press. 1984.

[35] Brumfit, Christopher. (Ed.) General English Syllabus Design. Pergamom Press. 1984

[36] Nunan, David. Syllabus design / David Nunan. SERBIULA (sistema Librum 2.0). 1988.

[37] Candlin, C. Syllabus design as a critical process. In C.J.
Brumfit (Ed.) General English Syllabus Design (pp.29-46). Pergamom Press. 1984.

[38] Breen, Michael P. Process Syllabuses for the Language Classroom. In C.J. Brumfit (Ed.) General English Syllabus Design (pp.47-60). Pergamom Press. 1984.

[39] Datzman, Brien. The Syllabus: An Opportunity for Reflection, Center for Language Studies, Nagasaki University. 2018.

[40] Dubin, F. and Olshtain, E. Course Design. Cambridge: Cambridge University Press. 1992.

[41] Antonietti, Alessandro \& Giorgetti, Marisa. Teachers' belief about learning from multimedia. Computers in Human Behavior. 22. 267-282. 10.1016/j.chb.2004.06.002. 2006.

[42] Bernard, H. R. Research methods in anthropology: Qualitative and quantitative approaches (4th ed.). Walnut Creek, CA: Alta Mira Press. 2002.

[43] Weitz, Darío. Diverging Bars, Why \& How: Storytelling with Divergences. Oct, 29 Retrieved from https://towardsdatascience.com/diverging-bars-why-how-3e 3ecc066dce on November 10, 2020.

[44] Ganti, Akhilesh. Correlation Coefficient. Online Available: https://www.investopedia.com/terms/c/correlationcoefficien t.asp on 01 September, 2020.

[45] Kumar, Deepak and Pushp Lata. Using Multimodal Tools for Teaching Multiliteracies in Indian ELT Classrooms. Interdisciplinary. Bloomsbury. New Delhi. pp 98-106 ISBN 978-93-88630-94-8. 2019.

[46] Hämäläinen, Raija \& Cattaneo, Alberto. New TEL Environments for Vocational Education - Teacher's Instructional Perspective. Vocations and Learning. 8. 10.1007/s12186-015-9128-1. 2015.

[47] Gressard, Clarice \& Loyd, Brenda. Age and Staff Development Experience with Computers as Factors Affecting Teacher Attitudes toward Computers. School Science and Mathematics. 85. 203 - 209. 10.1111/j.1949-8594.1985.tb09613.x. 2010.

[48] Demirdöken, Gökhan. A Need Analysis Study: Do Students Really Want to Share Their Desks with Technology? Universal Journal of Educational Research 7(12): 2699-2704, 2019. DOI: 10.13189/ujer.2019.071217. 